\title{
Bony metastases in desmoplastic pleural mesothelioma
}

\author{
T MACHIN, E T MASHIYAMA, J A M HENDERSON, W T E McCAUGHEY \\ From the Department of Pathology, St Mary Medical Center, Long Beach, California, USA; and the \\ Department of Medicine, Ottawa General Hospital, and Canadian Tumour Reference Centre, Ottawa Civic \\ Hospital, Ottawa, Canada
}

\begin{abstract}
Desmoplastic mesothelioma is an unusual variant of diffuse malignant mesothelioma in which much of the tumour is fibrous and which on this account may be difficult to distinguish from fibrous pleurisy. ${ }^{12}$ The clinical course is often rapid with metastases not infrequently occurring in liver, lung, adrenal, and kidney. Metastases in bone have only rarely been noted in desmoplastic mesothelioma, ${ }^{3}$ though they are known to occur in a small proportion of cases of the closely related sarcomatous mesothelioma. ${ }^{34}$

In this report we describe two cases of desmoplastic mesothelioma in which the pleural biopsy material resembled tissue with a reactive fibrosis, and which were unique in that osseous metastases were the first clinical evidence of tumour dissemination.
\end{abstract}

\section{Case reports}

\section{CASE 1}

A 78 year old man presented with a left pleural effusion. Thoracotomy showed pleural thickening of up to $1.0 \mathrm{~cm}$. Biopsy specimens were interpreted as showing fibrous pleurisy. Ten months later lytic lesions were found in the pelvic bones and the spine. An open biopsy of iliac crest showed fibrous tumour. Death occurred two months later. There was no history of exposure to asbestos. Necropsy was not performed.

The pleural biopsy specimens showed moderately cellular fibrous tissue in which the cells were frequently elongated and randomly arranged, and sometimes showed moderate pleomorphism and atypia (fig 1). Small areas of necrosis were present. At several points there was dense acellular hyaline collagen resembling that seen in fibrous pleural plaques. Pelvic bone biopsy showed fibrous tumour similar to that in the pleura (fig 2).

\section{CASE 2}

A 70 year old man with dyspnoea, chest tightness, cough, and right sided chest pain of several months' duration was found to have a right sided pleural effusion. Thoracotomy showed the right pleura to be thickened $(0.4-0.8 \mathrm{~cm})$ and to form a fixed pleural pocket. Biopsy specimens were interpreted as showing chronic pleuritis. Some five months later lytic areas were seen radiologically in both humeri, and bone scans showed areas of increased activity in these bones, in the

Address for reprint requests: Dr W T Elliott McCaughey, Canadian Tumour Reference Centre, Ottawa Civic Hospital, Ottawa, Ontario, Canada K1N 4M9.

Accepted 3 March 1987

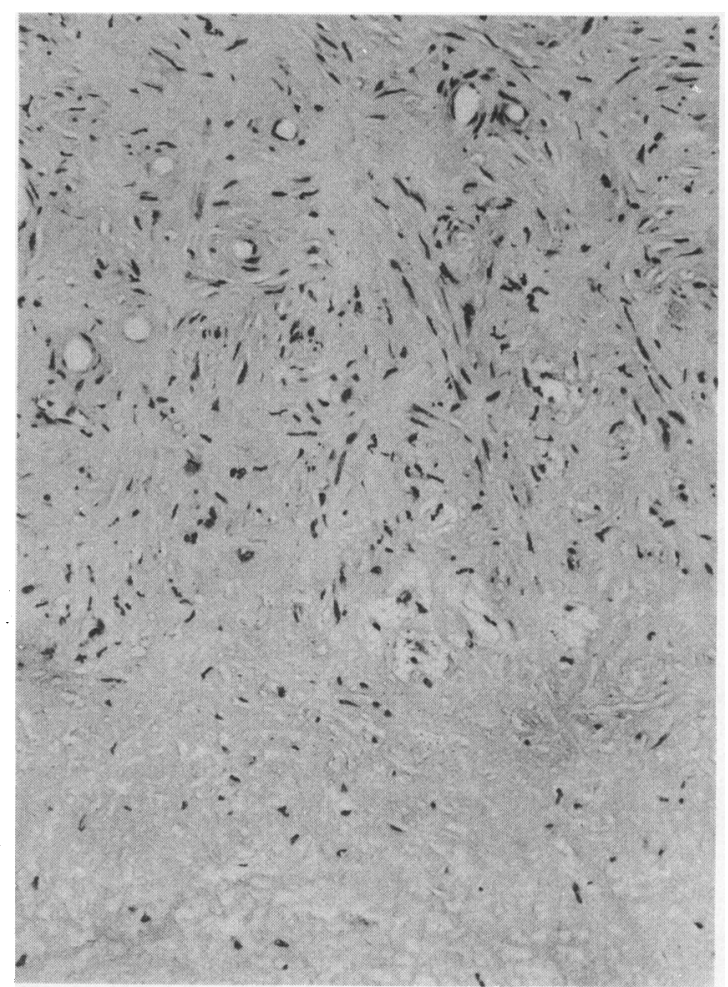

Fig 1 Case 1: Pleural desmoplastic mesothelioma, showing nuclear atypia and an area of necrosis in the lower part of the field.

femurs, and in the 8th ribs bilaterally. A biopsy was performed on a lesion in the right humerus. A month later the patient developed an acute pathological fracture of the left humerus. This was treated by surgical nailing but the patient died shortly afterwards. There was no necropsy.

The pleural biopsy specimens showed considerable fibrous thickening, the tissue in many areas being composed of fine, wire like hyaline strands of collagen disposed in interweaving bundles. Though mainly having poor cellularity, the tumour in places showed moderate cellularity with associated mild to moderate nuclear hyperchromasia and pleomorphism. The biopsy tissue from the right humerus was fibrous and mostly 


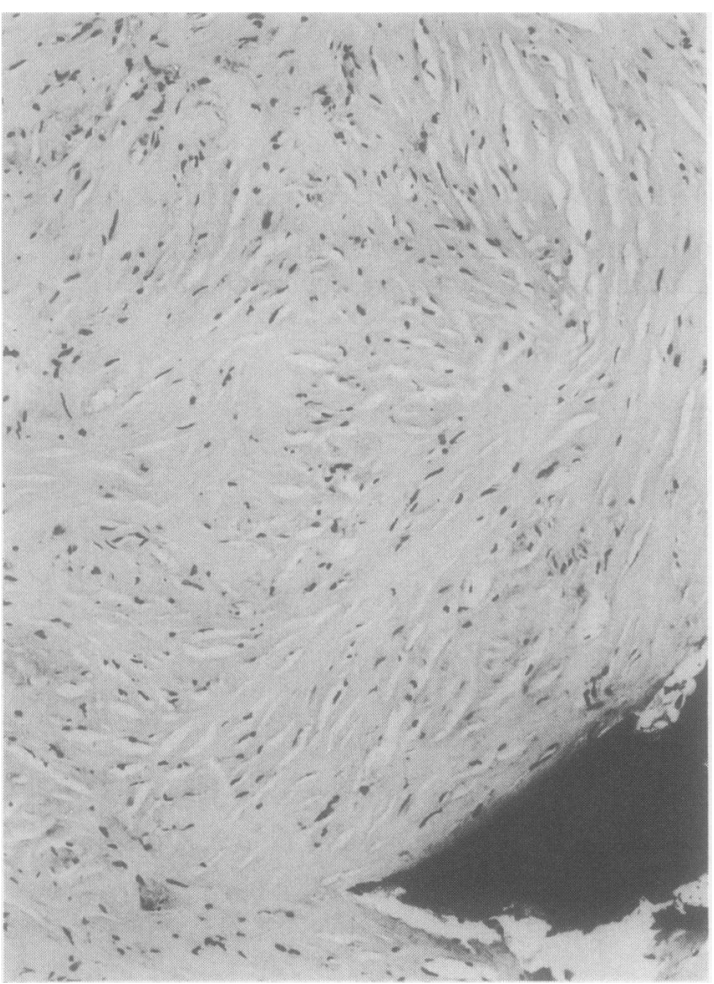

Fig 2 Case 1: Metastatic tumour in iliac bone, with a bone spicule (bottom right). The tumour is similar to that seen in figure 1 .

with poor cellularity. It also showed in some areas the same meshwork arrangement of fine strands of collagen that was seen in the pleural tumour.

\section{Discussion}

Differentiation of reactive serosal fibrosis and desmoplastic mesothelioma in pleural biopsy specimens is a not uncommon problem in our recent experience and one that is sometimes impossible to resolve in small biopsy specimens, and even occasionally in decortication specimens. The difficulty arises because desmoplastic mesotheliomas often contain extensive areas where the fibrous elements resemble scar tissue or organising pleurisy, and because fibrous pleurisy may show moderate cellularity and at least mild cytological atypia. Findings that favour a diagnosis of desmoplastic mesothelioma are: more than slight nuclear atypia; well developed fascicular, storiform, or other complex tissue patterns; necrosis; and infiltration of adjacent tissue. ${ }^{2}$ In both of our patients the pleural biopsy material was initially interpreted as showing fibrous pleurisy. Only when bony metastases developed did the neoplastic nature of the fibrous elements become clear. In retrospect, however, the presence of necrosis and nuclear atypia in the pleural tissue from the first patient and of nuclear atypia and is complex tissue patterns in that from the second patient provided important clues to the neoplastic nature of the desmoplastic pleural tissue. Both cases emphasise the potential for pathological misdiagnosis of diffuse pleural fibrous lesions.

Malignant pleural mesotheliomas of sarcomatous type metastasise more frequently to distant sites than epithelial forms of mesothelioma. ${ }^{4}$ As desmoplastic mesothelioma is usually a variant of sarcomatous mesothelioma it is not surprising that haematogenous metastases should develop. The uniqueness of our two cases lies in the occurrence of multiple bone metastases in the absence of clinical evidence of metastases at other sites. It was in fact only with their development that the neoplastic nature of the desmoplastic pleural tissue became clear.

\section{References}

1 Cantin RM, Al-Jabi M, McCaughey WTE. Desmoplastic diffuse mesothelioma. Am J Surg Pathol 1982;6: 215-22.

2 McCaughey WTE, Al-Jabi M. Differentiation of serosal hyperplasia and neoplasia in biopsies. In: Summers SC, Rosen PP, Fechner RE, eds. Pathology annual. Vol 21 (part 1). Norwalk, Connecticut: Appleton-CenturyCrofts, 1986:271-93.

3 Adams VI, Unni KK. Diffuse malignant mesothelioma of pleura. Diagnostic criteria based on an autopsy study. Am J Clin Pathol 1984;82:15-23.

4 Law MR, Hodson ME, Heard BE. Malignant mesothelioma of the pleura: relation between histological type and clinical behaviour. Thorax 1982;37:810-15. 